\title{
Generation Adequacy Assessment for Power Systems with Wind Turbine and Energy Storage
}

\author{
Ruimin Zheng, Student Member, IEEE, and Jin Zhong, Member, IEEE
}

\begin{abstract}
Wind power has been considered as an environmental friendly electrical generation resource; however, the high wind power penetration can lead to high-risk levels in power system reliability. Energy storage system (ESS) is a promising means to smooth variations of wind power and improve the system reliability. Simulation models for assessing generation adequacies of power systems with wind power generation system (WPGS) and ESS are presented in this paper. The impacts of different wind power penetration levels on the reliability benefits from ESS are analyzed in the first case-study, when the WPGS is utilized to replace the conventional generators with same total rated power capacity. In the second case-study, the WPGS and ESS are installed to meet the annual growth of load demand and maintain the generation adequacy levels. The Monte Carlo simulation is used to simulate the operation of generating units and ESS, considering the force outage rates (FOR) of generators and random fluctuations of wind speeds.
\end{abstract}

Index Terms--Energy storage system, Generation adequacy assessment, Power system reliability, Wind power generation.

\section{INTRODUCTION}

$\mathrm{W}$ ind power installation capacity has increased significantly worldwide in the past decades. This is benefited from the environmental and renewable energy policies. By replacing some fossil-fuel power generation capacities, wind power generation can effectively reduce the greenhouse emission. However, due to the intermittent characteristics of wind power, the fluctuations of wind power generation could have negative impacts on power grid operations. A day-to-day variation of wind power generation could be in the range from zero to near rated output, and an annual average capacity factor for a modern onshore wind farm is in the range of $30 \%-40 \%$ [1].

With the increase of wind power penetration in the grid, the adverse impacts of wind power fluctuations on power systems become significant. High wind power penetration can produce large power fluctuations and result in low system

This work was supported by the HKU Seed Funding Program for Basic Research (Project code: 20071159059), HKU Strategic Research Theme and the University Development Funding (Initiative on Clean Energy \& Environment).

Ruimin Zheng and Jin Zhong are with the Department of Electrical and Electronic Engineering, the University of Hong Kong, HKSAR, China (emails: rmzheng@eee.hku.hk, jzhong@eee.hku.hk ). reliabilities. Therefore, it is urgent to eliminate the variation to promote the application of wind power in power system. Energy storage system (ESS) has been an effective means to mitigate the generation fluctuations of intermittent power generation sources, such as wind power generation and photovoltaics [2]. Hence, ESS is introduced to alleviate wind power fluctuations and to maintain system reliability levels. There is a growing interest in using ESS to improve the reliabilities of power systems with wind turbines [3]-[5]. An ESS model appropriate for sequential simulation has been presented in [3]. Reference [4] presents a technique utilizing Monte Carlo simulation for the capacity adequacy evaluation of small isolated power systems including WPGS and ESS. The impacts of different operating strategies associated with WPGS and ESS on system generating adequacies have been studied using Monte Carlo simulation in [5]. However, the impacts of WPGS and ESS on system reliabilities have been analyzed by directly introducing WPGS and ESS into a system without changing load level and generation system configuration. Monte Carlo simulation has been considered as an effective method to analyze system generating capacity adequacy through simulating the actual process and random behavior of the system [6], [7].

This paper presents two cases to assess the generation adequacies of power systems including WPGS and ESS using Monte Carlo simulation, taking account of two objectives of installing WPGS. One objective is to replace the conventional power plant by WPGS, and other one is installing WPGS to meet the load growth and maintain the system adequacy. The Loss of Load Expectation (LOLE) is calculated as the adequacy index. Wind power penetration levels, capacities of ESS, and the growth rate of annual peak load are studied in details to evaluation the capacity benefits of WPGS and ESS.

This paper is organized as following. In Section II, the models are presented for assessing generation adequacy of power systems containing WPGS and ESS. In Section III, the systems with WPGS and energy storages are simulated using Monte Carlo simulation. Two case-studies with detailed result discussions are provided. Section IV is conclusions.

\section{Generation AdeQuacy Assessment}

One of the goals of generation adequacy assessment is to examine the abilities of system generating units meeting the 
load demand. The system model for adequacy evaluation of a generating system including wind energy and energy storage is shown in Fig.1.

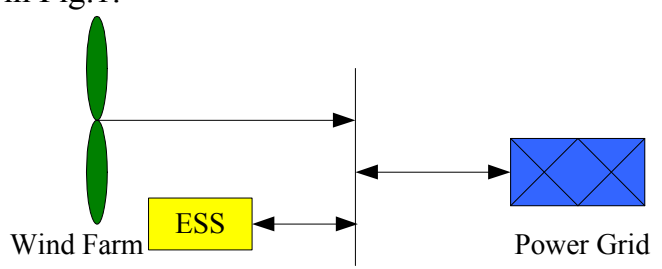

Fig. 1. System model for a power system containing wind power and ESS

The system could be simplified to a single bus, which connects the total generating units and total load, as shown in Fig. 2.

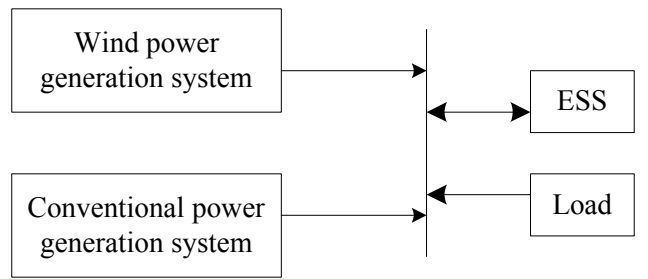

Fig. 2. Simplified model for power generation adequacy assessment study

A risk model for power system could be generated by combining generation model and load model [8]. The random sampling techniques are utilized to simulate the operation of conventional power generation system (CPGS) and WPGS, taking into account the FOR and random fluctuation of wind speed. A time series model of ESS is obtained by combining hourly total available generation of CPGS and WPGS with hourly load demand. Finally the system adequacy indexes could be calculated by the statistical method. The study process could be generalized as shown in Fig. 3 .

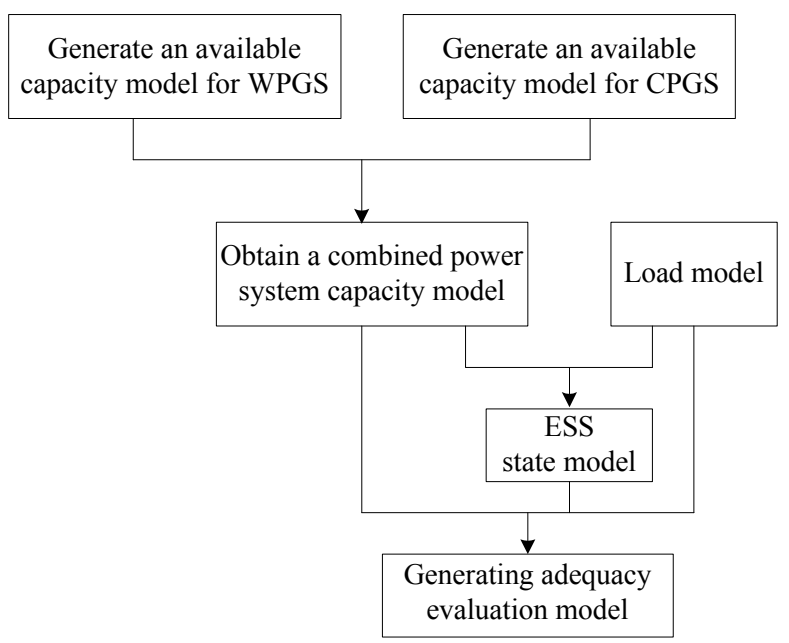

Fig. 3. Generation adequacy assessment study process for wind-conventional generating system including ESS

The LOLE is evaluated to analyze the system adequacy in various cases. The LOLE is the average number of days or hours in a given period in which the daily peak load or hourly load is expected to exceed the available generating capacity, as shown in (1) [8].

$L O L E=\sum_{i \in S} p_{i} T$

where, $p_{i}$ is the probability of system state $i$ and $S$ is the set of all system states associated with loss of load.

\section{A. Capacity model of generating units}

The generating units are modeled in two categories: WPGS and CPGS.

Conventional generating units can be modeled using the two-state model under the assumption that both operation time and maintenance time are exponentially distributed. Sampling values of time to failure (TTF) and time to repair (TTR) can be obtained by drawing random variables following the exponential distributions with mean time to failure (MTTF) and mean time to repair (MTTR), as shown in (2) and (3) [7].

$T T F=-M T T F \ln U$

$T T R=-M T T R \ln U^{\prime}$

where, $U$ and $U^{\prime}$ are uniformly distributed random number sequences in the range [0,1]. An up-and-down state model for the generating unit is obtained by sampling values of TTF and $T T R$, as shown in Fig. 4.

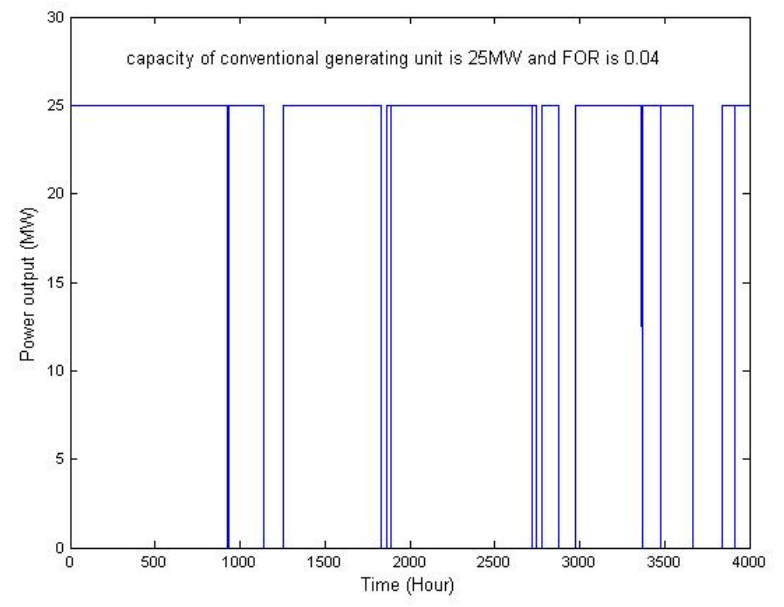

Fig. 4. Available capacity model for a generating unit in a sample period

The power output characteristics of WTG are different from those of conventional generators. The electric power output of a WTG in the up state depends strongly on the wind speed as well as on the performance characteristics of the generator [9]. Therefore, the output of WTG can be modeled by combining the two-state model and WTG power curve, shown as in (4) and Fig. 5.

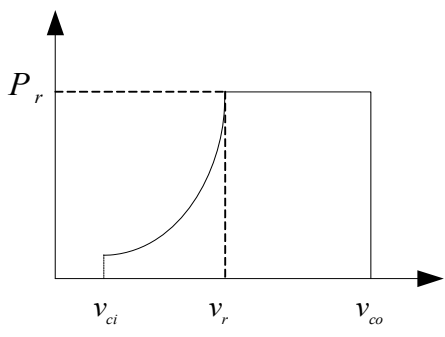

Fig. 5. Wind turbine generator power curve 
$P(v)=\left\{\begin{array}{cc}0 & 0 \leq v<v_{c i} \& \quad v \geq v_{c o} \\ a+b v^{m} & v_{c i} \leq v<v_{r} \\ P_{r} & v_{r} \leq v<v_{c o}\end{array}\right.$

$a=\frac{P_{r} \square v_{c i}^{m}}{v_{c i}^{m}-v_{r}^{m}}$

$b=\frac{P_{r}}{v_{r}^{m}-v_{c i}^{m}}$

where $v_{c i}, v_{r}, v_{c o}$ are the cut-in, rated and cut-out wind speeds respectively, $m$ is the order of the output characteristic curve and $P_{r}$ is the rated capacity of the WTG.

The wind speed could be treated as a random variable and assumed to be distributed as Rayleigh distribution given by following probability density function [10]:

$f(v)=\frac{2}{c}\left(\frac{v}{c}\right) \exp \left[-\left(\frac{v}{c}\right)^{2}\right]$

There is a direct relationship between scaling factor $c$ and average wind speed $\bar{v}$.

$c \cong 1.128 \bar{v}$

Combining the two-state model and WTG power curve, we can obtain the WPGS capacity model, as shown in Fig.6.

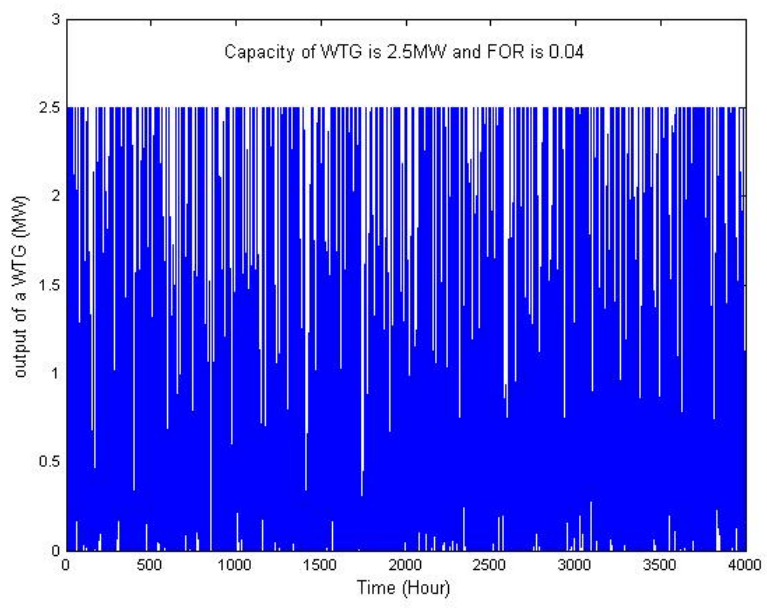

Fig. 6. Available capacity model for a wind power generating unit in a sample period

\section{B. Load model}

The IEEE RTS load model is used to produce system hourly loads for a year, as in (9) [8].

$L(t)=L_{y} \times P_{w} \times P_{d} \times P_{h}(t)$

Where $L_{y}$ is the annual peak load, $P_{w}$ is the percentage of weekly load in terms of the annual peak load, $P_{d}$ is the percentage of daily load in terms of the weekly peak load and $P_{h}(t)$ is the percentage of hourly load in terms of the daily peak load. The annual hourly load curve could be developed from (9), when the above mentioned parameters are determined. Fig. 6 shows a typical annual hourly load curve of the IEEE RTS system, when annual peak load equals to 800MW.

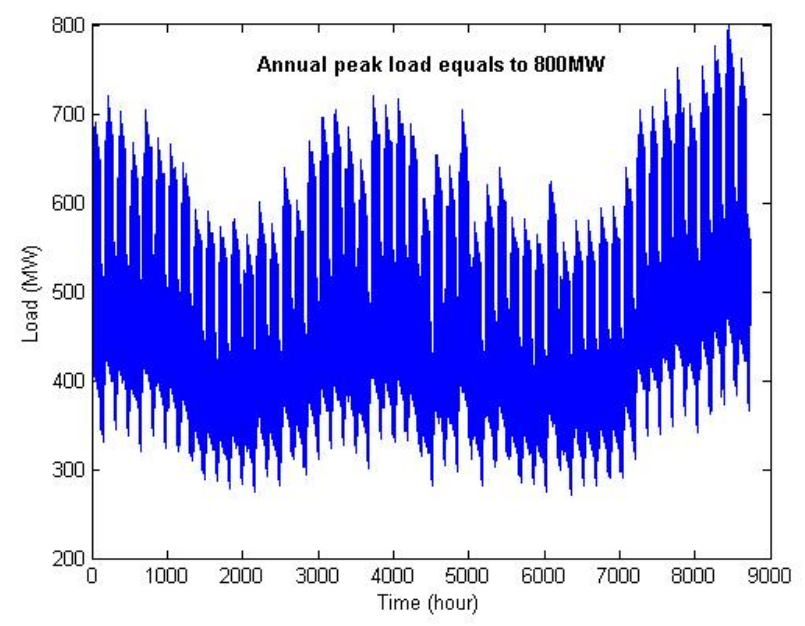

Fig. 6. Annual hourly load curve of IEEE RTS

\section{Energy state model of ESS}

The ESS could be operated either by the power system operator or a wind farm owner. There are three possible operating strategies for wind farm and ESS [5]. In this paper, we assume that the ESS is operated following the simple rules: 1) the surplus energy will be stored if the sum of wind power generation and conventional power generation exceeds the system demand, and 2) the stored energy will be used if generation is not enough to supply demand.

The ESS is defined by its energy capacity, charging and discharging rates, and charging and discharging efficiencies. The relationships between energy state series of ESS and surplus power are given as follows:

$$
\begin{aligned}
& E S(t+1)= \begin{cases}E S(t)+\frac{1}{\eta_{d}} S P(t) \Delta t & (S P(t) \leq 0) \\
E S(t)+\eta_{c} S P(t) \Delta t & (S P(t)>0)\end{cases} \\
& S P(t)=W G(t)+C G(t)-L(t) \\
& -D R \leq S P(t) \leq C R \\
& E S_{\text {min }} \leq E S(t) \leq E S_{\text {max }}
\end{aligned}
$$

where, $E S(t)$ is the energy state series of ESS, $S P(t)$ is the surplus power; $\eta_{d}$ and $\eta_{c}$ are the discharging efficiency and charging efficiency of ESS, respectively; $W G(t)$ and $C G(t)$ are the output power of WPGS and CPGS, respectively; $D R$ and $C R$ are the discharging and charging rates of ESS, respectively; and $E S_{\min }$ and $E S_{\max }$ are the minimum and maximum capacity of ESS.

Therefore, the ESS model can be obtained from the load time series and the total generation time series using (10)-(13).

\section{CASE STUdies}

Numerical examples are studied for installing wind power in a power system with two different objectives: One objective is to replace conventional power plants with Wind Turbine Generators (WTGs), and other one is installing WTGs to meet the load growth and maintain the system capacity adequacy. 


\section{A. Replacing coal-fired power generators with WTGs and} ESS

In this case study, the parameters of conventional generators were designed on the basis of IEEE RTS generator data. The generation system rated capacity is $1000 \mathrm{MW}$. The conventional generating unit ratings and reliability data are presented in Table I.

TABLE I

CONVENTIONAL GENERATING UNIT RELIABILITY DATA

\begin{tabular}{c|c|c|c|c|c}
\hline $\begin{array}{c}\text { Unit } \\
\text { No. }\end{array}$ & $\begin{array}{c}\text { Unit Size } \\
(\mathrm{MW})\end{array}$ & Unit Type & FOR & MTTF & MTTR \\
\hline 1 & 25 & Combustion turbine & 0.1 & 450 & 50 \\
\hline 2 & 100 & Oil-fired power plant & 0.02 & 1960 & 40 \\
\hline 3 & 150 & Oil-fired power plant & 0.02 & 1960 & 40 \\
\hline 4 & 150 & Oil-fired power plant & 0.02 & 1960 & 40 \\
\hline 5 & 325 & Nuclear power plant & 0.12 & 1960 & 40 \\
\hline $6-15$ & $25 * 10$ & Coal-fired power plant & 0.04 & 960 & 40 \\
\hline
\end{tabular}

The power output of WPGS depends on the wind power density of the location of a wind farm. The power density indicates the amount of energy that is available at the site for conversion by a wind turbine. The wind power densities at different wind power classes measured at $10 \mathrm{~m}$ and $50 \mathrm{~m}$ are listed in Table II [11].

TABLE II

CLASSES OF WIND POWER DENESITY AT $10 \mathrm{~m}$ AND $50 \mathrm{~m}$

\begin{tabular}{|c|c|c|c|c|}
\hline \multirow{2}{*}{$\begin{array}{l}\text { Wind } \\
\text { power } \\
\text { class }\end{array}$} & \multicolumn{2}{|l|}{$10 \mathrm{~m}$} & \multicolumn{2}{|l|}{$50 \mathrm{~m}$} \\
\hline & $\begin{array}{l}\text { Wind power density } \\
\left(\mathrm{W} / \mathrm{m}^{2}\right)\end{array}$ & $\begin{array}{c}\text { Speed } \\
(\mathrm{m} / \mathrm{s})\end{array}$ & $\begin{array}{l}\text { Wind power density } \\
\qquad\left(\mathrm{W} / \mathrm{m}^{2}\right)\end{array}$ & $\begin{array}{c}\text { Speed } \\
(\mathrm{m} / \mathrm{s})\end{array}$ \\
\hline 1 & $<100$ & $<4.4$ & $<200$ & $<5.6$ \\
\hline 2 & $100-150$ & 5.1 & $200-300$ & 6.4 \\
\hline 3 & $150-200$ & 5.6 & $300-400$ & 7.0 \\
\hline 4 & $200-250$ & 6.0 & $400-500$ & 7.5 \\
\hline 5 & $250-300$ & 6.4 & $500-600$ & 80 \\
\hline 6 & $300-400$ & 7.0 & $600-800$ & 8.8 \\
\hline 7 & $>400$ & $>7.0$ & $>800$ & $>8.8$ \\
\hline
\end{tabular}

In general, sites with a wind power class rating at 4 or higher are currently preferred for large scale wind plants. Thus, the location for wind farm is selected with an average wind speed at $7.5 \mathrm{~m} / \mathrm{s}$. According to (8), the scale parameter of wind speed distribution equals to 8.5 approximately, if the tower height of WTGs is $50 \mathrm{~m}$.

The Nordex N90 is used as the WTG studied in this case study. Its rated output is $2.5 \mathrm{MW}$. The cut-in, rated and cut-out wind speeds are 4,13 and $25 \mathrm{~m} / \mathrm{s}$, respectively. At present, the FOR of WTG is still unavailable. In order to eliminate the impacts of FORs on the results of reliability analysis, the FOR of WTG is set to be 0.04 , which is equal to the FOR of coalfired generators.

The maximum and minimum capacities of the ESS are $100 \%$ and $20 \%$ of its rated capacity, respectively. The charging and discharging rates are considered to be linear in a 6-hour charging and discharging period. The charging efficiency and discharging efficiency are assumed to be $80 \%$.

The coal-fired generating units are removed one by one from the system and replaced by WTGs with equal capacities as the removed units. The results are given in Fig. 7, which shows the LOLE changes with respect to the increase of wind power capacity.

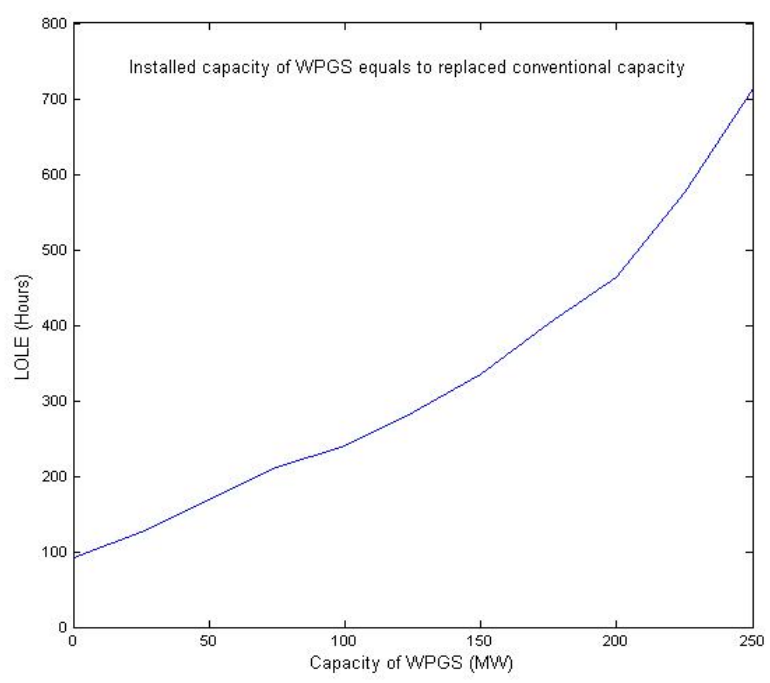

Fig. 7. LOLE versus capacity of WPGS

In Fig.7, we can see that the value of LOLE increases with the increasing replacement capacity of coal-fired units (or increasing capacity of WPGS). The relationship of the LOLE and the WPGS capacity is approximately a linear function when the wind power penetration level is lower than $20 \%$ (200 MW out of 1000 MW in Fig.7). When the penetration level exceeds $20 \%$, the LOLE of the system has an abrupt increase as shown in Fig. 7. Therefore, the suggested maximum wind power share in a power grid should be $20 \%$, based on the adequacy assessment.

The ESS was added in the system to mitigate the adverse effect of WTGs on the system reliability. The ESS is installed with the target to maintain the original level of system adequacy, i.e. LOLE of 92.36 hours/year. The relationships between ESS capacity and LOLE under different wind power penetration levels, $5 \%, 10 \%$ and $20 \%$, are simulated and shown in Fig. 8.

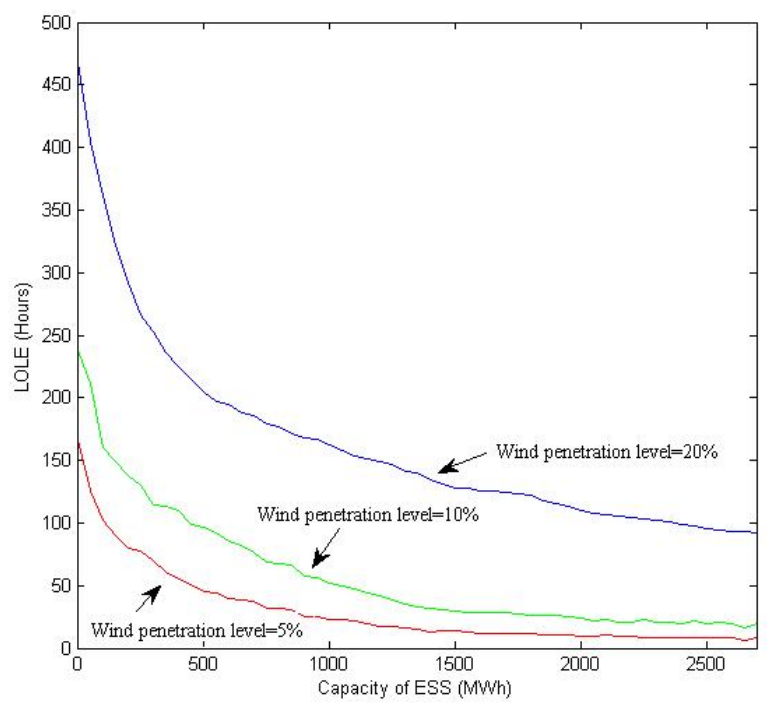

Fig. 8. LOLE versus capacity of ESS under different penetration levels 
As shown in the Fig.8, adding ESS can significantly improve system capacity adequacy. However, the improvement tends to be saturate, when the capacity of ESS reaches specific threshold. When the wind penetration level reaches $5 \%, 10 \%$ and $20 \%$, approximate threshold values of ESS capacity are $1500 \mathrm{MWh}, 2000 \mathrm{MWh}$ and $2500 \mathrm{MWh}$, respectively. Therefore, the capacity of ESS should be less than the threshold value, so as to avoid saturation and maximize the benefits of ESS.

The desired capacity of ESS with respect to wind power penetration level has also been studied under different LOLE requirements, as shown in Fig. 9.

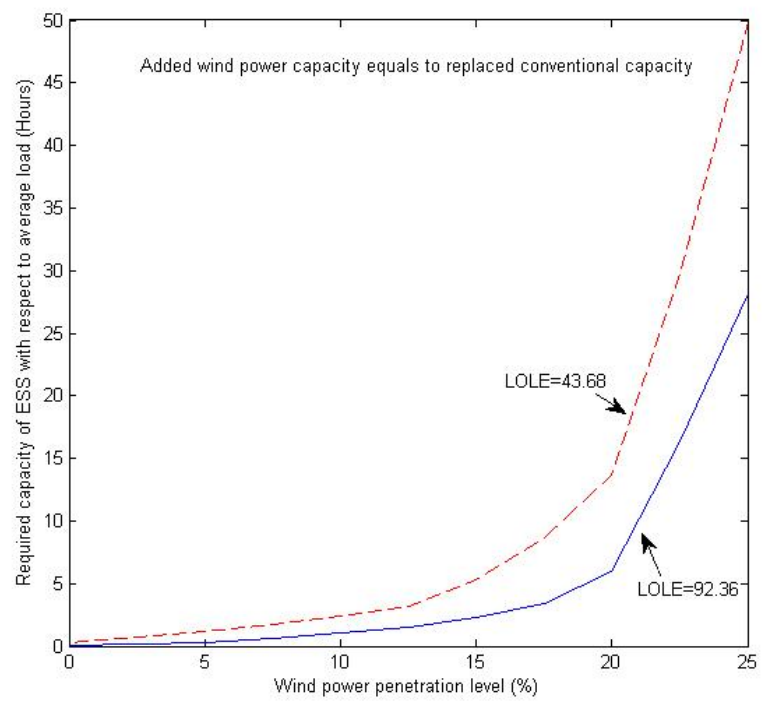

Fig. 9. Required capacity of ESS versus wind power penetration level

With the increase capacity of wind power generation, the desired capacity of ESS is growing quickly, especially when the ratio of wind power is larger than $20 \%$. The dotted line shows the required capacities of ESS at different wind power penetration levels, in order to improve the LOLE to 43.68 hours/year. The dotted line also indicates that adding more capacity of ESS could improve the system reliability, and the extra needed capacity of ESS also increases with the wind power penetration level. Similarly, the wind power penetration level should be less than $20 \%$ due to the reliability constraints and benefit of ESS.

\section{B. Installing WTGs and ESS to meet annual growth of load demand}

In this case study, the system data is almost the same as case A, except that the 10 coal-fire plants were simulated using one equivalent coal-fire plant with a capacity of 250MW. Thus the LOLE of the base system is 99.01 hours/year. The rated capacity of system is $1000 \mathrm{MW}$ and the annual peak load is $800 \mathrm{MW}$. The annual load growth is represented by the growth of annual peak load in this work. The annual growth of load depends on the economic growth of areas. Three growth rates $0.01,0.05$ and 0.09 represent undeveloped, developed and developing regions are tested.

Three expansion scenarios of the generation system are also studied to analyze the load-carrying ability of wind power. No generation capacity is added in the scenario 1, while the added capacity of WTGs and conventional generators equals to the growth of annual peak load in the scenario 2 and scenario 3 . The system adequacy index of different expansion plan is calculated and shown in the Table III and Fig. 10.

TABLE III

LOLE OF DIFFERENT EXPANSION PLAN WITH DIFFERENT GROWTH RATE OF PEAK LOAD

\begin{tabular}{c|c|c|c|c}
\hline \multirow{2}{*}{$\begin{array}{c}\text { Growth } \\
\text { rate } \\
(\%)\end{array}$} & \multirow{2}{*}{$\begin{array}{c}\text { Peak Load } \\
\text { Growth } \\
(\mathrm{MW})\end{array}$} & \multicolumn{3}{|c}{$\begin{array}{c}\text { LOLE } \\
\text { (Hours) }\end{array}$} \\
\cline { 3 - 5 } & & scenario 1 & scenario 2 & scenario 3 \\
\hline 1 & 8 & 110.1 & 106.3 & 96.61 \\
\hline 5 & 40 & 159.8 & 141.8 & 87.28 \\
\hline 9 & 72 & 218.3 & 188.1 & 81.03 \\
\hline
\end{tabular}

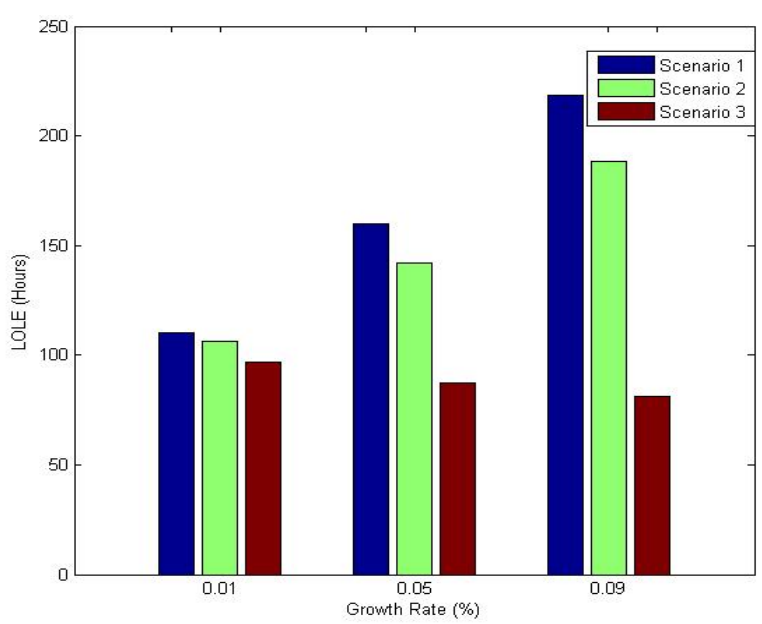

Fig. 10. LOLE versus load growth rate with different expansion plan

The Fig. 10 shows that adding wind power could improve the system reliability when peak load grows. However, the load-carrying of wind power generation is not strong as conventional generation due to the variable wind speed. It may also been seen from Fig. 10 that the difference between scenario 2 and scenario 3 becomes significant as the peak load growth rate increase.

In order to maintain the original level of system adequacy, sufficient generation was added into the system. The required capacity of generating unit in scenario 2 and scenario 3 has been calculated, as shown in the Table IV.

TABLE IV

REQUIRED CAPACITY OF GENERATING UNIT TO MEET THE SYSTEM ADEQUACY LEVE

\begin{tabular}{c|c|c|c|c|c}
\hline \multirow{2}{*}{$\begin{array}{c}\text { Growth } \\
\text { rate } \\
(\%)\end{array}$} & $\begin{array}{c}\text { Growth of } \\
\text { peak load } \\
(\mathrm{MW})\end{array}$ & \multicolumn{2}{|c|}{$\begin{array}{c}\text { Wind power } \\
\text { generation }\end{array}$} & \multicolumn{2}{c}{$\begin{array}{c}\text { Conventional } \\
\text { generation }\end{array}$} \\
\cline { 3 - 6 } & $\begin{array}{c}\text { Capacity } \\
(\mathrm{MW})\end{array}$ & $\begin{array}{c}\text { Time } \\
\mathrm{s}\end{array}$ & $\begin{array}{c}\text { Capacity } \\
(\mathrm{MW})\end{array}$ & Times \\
\hline 1 & 8 & 24 & 3 & 5.5 & 0.688 \\
\hline 5 & 40 & 180 & 4.5 & 33 & 0.825 \\
\hline 9 & 72 & 520 & 7.2 & 60 & 0.833 \\
\hline
\end{tabular}

There is a nonlinear relationship between the increase of 
power generation capacity and growth of peak load. With same peak load growth, required wind power capacity is much more than the conventional capacity. When the growth rate is $9 \%$, the desired capacity for scenario 2 and scenario 3 is $520 \mathrm{MW}$ and $60 \mathrm{MW}$. Meanwhile, the penetration level of wind power reaches up to $34.2 \%$, which is adverse to the system reliability. Therefore, merely installing wind power generation could not satisfy the growing load demand in the developing regions, such as china. This conclusion agrees with the current state of China's power system construction that WPGS acts as a supplement to CPGS when electricity shortage occurs [12].

If the ESS is introduced into scenario 2, the required wind power capacity would be greatly reduced due to the peak load shifting ability of ESS. In order to decrease the required capacity of wind power and maintain the system reliability level, the desired ESS capacity with respect to different peak load growth rate has been calculated, as shown in Table V.

TABLE $\mathrm{V}$

CAPACITY COMBINATONS OF WIND POWER GENERATION AND ESS

\begin{tabular}{|c|c|c|c|}
\hline \multirow{2}{*}{$\begin{array}{c}\text { Growth rate } \\
(\%)\end{array}$} & \multirow{2}{*}{$\begin{array}{l}\text { Growth of } \\
\text { peak load } \\
\text { (MW) }\end{array}$} & \multicolumn{2}{|c|}{ Capacity } \\
\hline & & $\begin{array}{l}\text { Wind power } \\
\text { (MW) }\end{array}$ & $\begin{array}{c}\text { ESS } \\
\text { (MWh) }\end{array}$ \\
\hline \multirow[t]{2}{*}{0.01} & \multirow[t]{2}{*}{8} & 8 & 11.4 \\
\hline & & 16 & 4.018 \\
\hline \multirow[t]{2}{*}{0.05} & \multirow[t]{2}{*}{40} & 40 & 60 \\
\hline & & 80 & 25.85 \\
\hline \multirow[t]{2}{*}{0.09} & \multirow[t]{2}{*}{72} & 72 & 148.6 \\
\hline & & 144 & 66.4 \\
\hline
\end{tabular}

Comparing the data of Table $\mathrm{V}$ and Table IV, we can see that adding ESS could effectively decrease the needed capacity of wind power. As shown in the Table V, 66.4MWh ESS could save the wind power capacity up to $376 \mathrm{MW}$. If the unit cost of wind power and ESS are available, the optimal portfolio for wind power and ESS could be obtained at different growth rate of peak load.

\section{CONCLUSIONS}

This paper uses Monte Carlo simulation to assess generation adequacies of power systems with wind turbine and energy storage. Two case-studies are presented with consideration of different purposes of installing WPGS.

When the coal-fired generators are replaced by the WPGS with equal capacities as the removed units, the LOLE increases along with the increasing replaced capacities of coal-fired units. Adding ESS can significantly improve system capacity adequacy. Results indicate that the suggested wind power penetration level is lower than $20 \%$, in view of the generation adequacy constraints and benefits of ESS.

Installing WPGS can improve the system reliability when peak load grows. However, WPGS could not economically satisfy the growing load demand by itself in the developing regions, because of the load-carrying ability of wind power generation is weaker than conventional generation. The required capacity of WPGS can be greatly decreased by ESS at different growth rate of peak load. Therefore, economical capacity combination of WPGS and ESS, in terms of generation adequacy, could be figure out in the future study.

This work could assist power system planners and utility managers to evaluate the capacity benefits of WPGS and ESS.

\section{REFERENCES}

[1] L. Söder, T. Ackermann, "Wind power in power systems: an introduction," in Wind Power in Power Systems, T. Ackermann, Ed. England: John Wiley \& Sons, 2005, pp. 25-47.

[2] P. Riberio, B. Johnson, M. Crow, A. Arsoy, and Y. Liu, "Energy storage systems for advanced power applications," Proceedings of the IEEE, vol.89, pp. 1744-1756, 2001.

[3] M. Korpaas, A. Holen, and R. Hildrum, "Operation and sizing of energy storage for wind power plants in a market system," International Journal of Electrical Power and Energy Systems, vol. 25, pp. 599-606, 2003.

[4] Bagen and R. Billinton, "Reliability cost/worth associated with wind energy and energy storage utilization in electric power systems," Probabilistic Method Applied to Power Systems, 2008. PMAPS'08. Proceedings of the $10^{\text {th }}$ International Conference on, 2008, pp. 1-7.

[5] P.Hu, R.Karki, and R. Billinton, "Reliability evaluation of generating systems containing wind power and energy storage," IET Gener. Transm. Distrib., vol.3, pp.783-791,2009

[6] R. Billinton and R. Karki, "Application of Monte Carlo simulation to generating system well-being analysis," IEEE Trans. Power Systems, vol.14, pp. 1172-1177, Aug. 1999.

[7] R. Billinton and W. Li, Reliability Assessment of Electric Power Systems Using Monte Carlo Methods, New York: Plenum, 1994.

[8] R. Billinton and R. Allan, Reliability Evaluation of Power Systems, 2nd ed., New York: Plenum, 1996.

[9] S. Karaki, R. Chedid, and R.Ramadan, "Probabilistic performance assessment of wind energy conversion systems," IEEE Trans. Energy Conversion, vol.14, pp. 217-224, Jul. 1999.

[10] G. Masters, Renewable and Efficient Electric Power Systems, New Jersey: John Wiley \& Sons, 2004.

[11] "Basic principles of wind resource evaluation," [Online]. Available: http://www.awea.org/faq/basicwr.html.

[12] M. Wang and J. Zhong, "Development of distributed generation in China," in Proc. 2009 IEEE Power \& Energy Society General Meeting, pp.1-7.

\section{BIOGRAPHIES}

Ruimin Zheng received the B.Sc. degree from North China Electric Power University, China in 2005 and M.Sc. degree from Xian Jiaotong University, China in 2008. She is now a PhD student in the Department of Electrical and Electronic Engineering, the University of Hong Kong. Her main field of interest is renewable energy, wind power, energy storage system, and smart grid.

Jin Zhong (M'04) received the B.Sc. degree from Tsinghua University, Beijing, China, in 1995, the M.Sc. degree from China Electric Power Research Institute, Beijing, in 1998, and the $\mathrm{PhD}$ degree from Charmers University of Technology, Gothenburg, Sweden, in 2003. At present, she is an Assistant Professor in the Department of Electrical and Electronic Engineering of the University of Hong Kong. Her areas of interest are electricity sector deregulation, ancillary service pricing, and distributed generation. 